\title{
Comparison of outcomes and analysis of risk factors for non-union in locked plating of closed periprosthetic and non- periprosthetic distal femoral fractures in a retrospective cohort study
}

\author{
James Karam ${ }^{1 *}$, Paul Campbell ${ }^{1}$, Michael David ${ }^{2}$ and Michael Hunter ${ }^{1}$
}

\begin{abstract}
Background: The primary aim was to compare the outcomes of locked plating of closed distal femur periprosthetic and non-periprosthetic fractures by testing the hypothesis that outcomes would be worse in the periprosthetic group. The secondary aim of this study was to identify risk factors for non-union.

Methods: A single-center study over an 8-year period utilizing a retrospective cohort design was performed. Sixtyeight patients with periprosthetic fractures and 57 patients with non-periprosthetic fractures met inclusion criteria for the study. There was a significant difference between groups in mean age (80.1 years periprosthetic vs. 70.9 years nonperiprosthetic $(p<0.001)$ ). Statistical analysis between groups was used to assess the outcomes of time to union, incidence of non-union, post-operative functionality, incidence of complications, progression to revision surgery, and mortality. A secondary multivariable analysis was used to assess risk factors for non-union and factors positively associated with union.

Results: There were no significant differences in outcomes between groups. Union rates were $83.8 \%$ (57/68) in the periprosthetic group and $78.9 \%(45 / 57)$ in the non-periprosthetic group $(p=0.648)$. Comminution was identified as a significant risk factor for non-union $(p=0.005)$. Use of a submuscular technique had a significant positive association with union $(p=0.006)$.
\end{abstract}

Conclusions: Outcomes of surgical treatment for periprosthetic and non-periprosthetic distal femur fractures are similar. There is a significant risk of non-union in locked plating of both groups.

Keywords: Distal femur fracture, Periprosthetic fracture, Total knee arthroplasty, Locking plate fixation, Non-union, Comminution

\section{Background}

Distal femur periprosthetic fractures have become a more common complication in association with increased rates of knee arthroplasty in an aging population [1]. The incidence of periprosthetic fracture is reported as $0.3-2.5 \%$ [2]. The rate of total knee arthroplasty in Australia as recorded on a national registry has increased $139.8 \%$ since

\footnotetext{
* Correspondence: jameseliaskaram@gmail.com

${ }^{1}$ Gosford District Hospital, Central Coast Local Health District, Gosford, NSW 2250, Australia

Full list of author information is available at the end of the article
}

2003 [3]. The majority of these fractures are treated operatively, with locked plating a commonly used modality [4]. Other treatment options include retrograde intramedullary nailing and distal femoral arthroplasty as a primary treatment. There is no clear consensus on the optimal surgical intervention [5].

The aims of surgical treatment are to achieve stable anatomical reduction allowing for analgesia, ease of care, and early mobilization $[6,7]$. These fractures have been shown to have problematic healing, with reported nonunion rates of $6-25 \%[8,9]$. Other known problems

(c) The Author(s). 2019 Open Access This article is distributed under the terms of the Creative Commons Attribution 4.0 International License (http://creativecommons.org/licenses/by/4.0/), which permits unrestricted use, distribution, and 
associated with these fractures include decreased mobility and loss of independence in more than $50 \%$ of patients, a $3-37 \%$ risk of post-operative complication, and an up to $25 \%$ rate of 1 -year mortality [10-13].

In most instances, periprosthetic fractures are treated similarly to their non-periprosthetic counterparts, where this fracture is common in the elderly osteoporotic population. To date, there has been little in the way of direct comparison of outcomes of both groups [14].

The hospital for this study, located in an area with a large retired population, has treated a large number of these fractures. The primary aim of this study was to compare the outcomes of surgical treatment, specifically locked plating, of periprosthetic and non-periprosthetic fractures. The secondary aim was to determine predictors of non-union and union in both groups.

It was hypothesized that overall outcomes in locked plating of periprosthetic fractures would be worse than their non-periprosthetic counterparts. Based on 2017 Australian registry data recording an average age at primary knee arthroplasty of 68.7 years and $92.7 \%$ of patients classified as American Society of Anesthesiologists (ASA) score 2 or 3 [3], it was hypothesized that patients with periprosthetic fractures may represent an older and more frail population than a non-periprosthetic fracture population. The overall value of this study will add to existing knowledge about this fracture and help aide surgeons in determining a common approach to both fracture groups.

\section{Methods}

Local health district ethics approval was attained for the purpose of performing a retrospective cohort analysis of patients with distal femoral fractures treated in a single hospital from 2011 to 2018. A search was performed through the hospital medical records department using diagnosis-related group (DRG) codes for distal femoral and related fractures [15].

A flowchart of patients identified as eligible for the study can be found in Fig. 1. All patients aged 16 and above with either extra or intra-articular distal femoral fractures around either a prosthetic or non-prosthetic knee treated with locked plating only were included. Open fractures, pediatric fracture patterns, partial articular fractures (including Hoffa fractures, isolated condyle fractures, and intracondylar splits), fractures around a unicompartmental knee replacement, and fractures in non-ambulant patients were excluded. Patients who were treated non-operatively or with another modality (including retrograde intramedullary nail and distal femoral replacement) were also excluded.
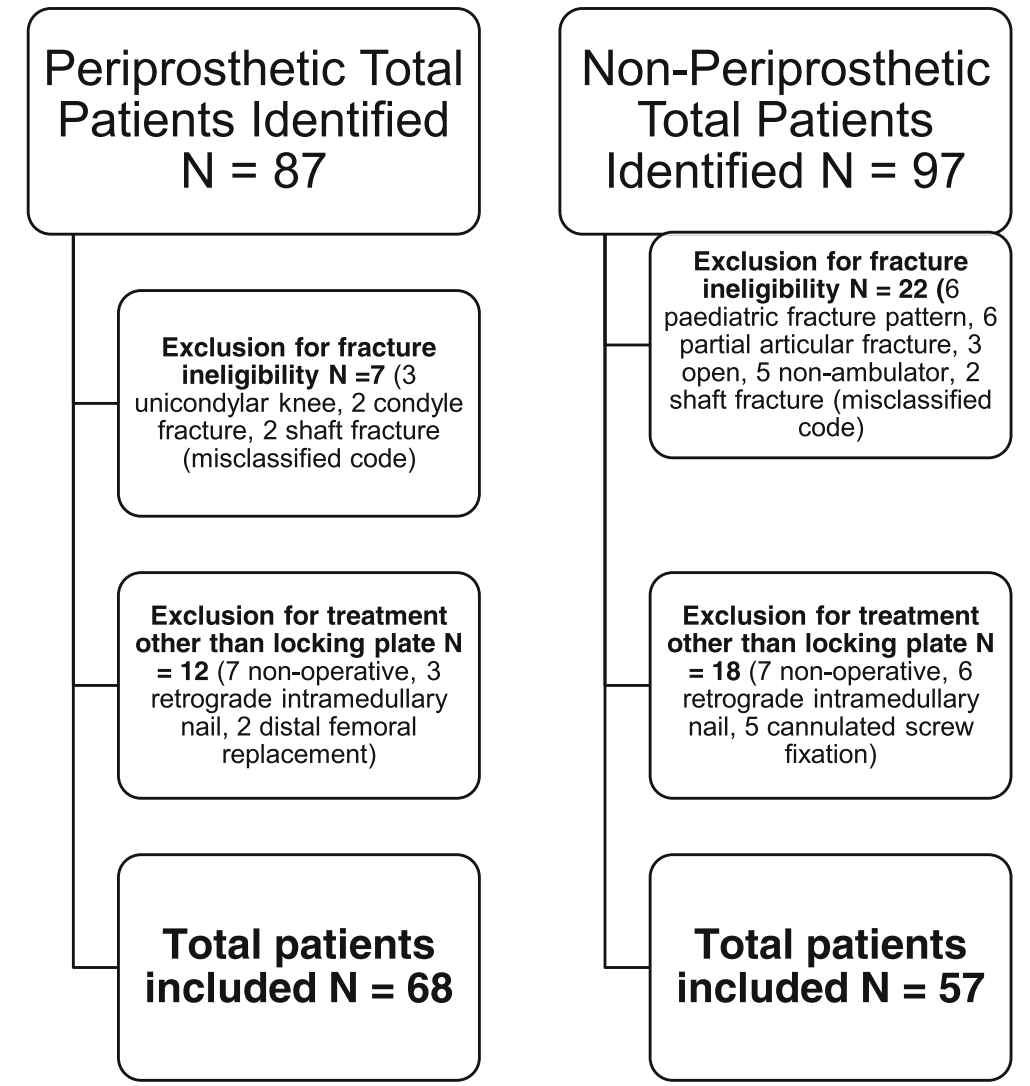

Fig. 1 Patient selection 
All patients received anteroposterior (AP) and lateral $\mathrm{x}$ rays at presentation to the emergency department and at follow-up. Computed tomography scans were obtained in the majority of patients to aid pre-operative planning. All fractures were sustained following low-energy falls. Fractures were classified according to the Arbeitsgemeinschaft für Osteosynthesefragen/Orthopedic Trauma Association (AO/ OTA) system for distal femur fractures [16]. Fracture comminution was defined as the presence of at least one separate metaphyseal or diaphyseal cortical bone fracture fragment (AO/OTA classification 33A2 or 3 and $33 \mathrm{C} 2$ or 3).

Surgery was performed either by consultant surgeons or trainees under consultant supervision. All patients received locking plate fixation using the stainless steel condylar locking compression plate (LCP) 4.5/5.0 (DePuy Synthes, Oberdorf, Switzerland). Surgery performed with exposure of the fracture was recorded as 'open' and surgery using a minimally invasive plate osteosynthesis (MIPO) technique was recorded as 'submuscular' [17]. Plate length and working length in plate holes was recorded. Working length was defined as the distance in plate holes between the proximal and distal most screws on each side of the fracture. All patients received routine pre- and postoperative antibiotics and anticoagulation and were made non-weightbearing for a minimum of 6 weeks postoperatively.

Follow up took place at 2 weeks, 6 weeks, 3 months, and 6 months. Union was defined as the presence of a minimum of three out of four bridging cortices on AP and lateral $x$-rays at 6 month follow up [18]. Patients who missed their 6-month follow up yet went on to unite had 'time to union' recorded at the time of their last follow up. $\mathrm{X}$-rays failing to meet the minimum requirement of bridging cortices at 6 months were recorded as non-unions. These patients had extended follow up with further $\mathrm{x}$-rays confirming the presence of non-union.

Complications recorded included hardware failure, wound or periprosthetic infection, peri-implant fracture, symptomatic hardware prominence, and the incidence of deep vein thrombosis in the post-operative period. Postoperative function was determined based on mobility and dependence status at last follow up or most recent hospital visit. Decreased function was recorded if the patient had become dependent on a walking aid or if they could no longer live independently (including placement in an aged care facility). Mortality was recorded through the scrutinization of patient records on an electronic record system.

Descriptive statistics recorded included means and standard deviations for continuous variables and counts (percentages) for categorical variables. Statistical analysis of outcomes between groups was performed using Pearson Chi-square tests comparing the incidence of nonunion, post-operative functionality, incidence of complications, progression to revision surgery, and mortality. A survival analysis using competing risk modeling was applied to the comparative analysis of time to union. An analysis of risk factors for non-union and factors positively associated with union was performed using a Firth stepwise logistic regression model with an inclusion threshold of 0.2. The assumption of proportional hazards and appropriate model specified were assessed using the Hosmer-Lemeshow test and the Pregibon link test respectively. All tests were two-sided and had a 0.05 level of significance. Statistical analysis was performed using STATA Version 15 software (StataCorp LLC, College Station, Texas United States of America).

\section{Results}

\section{Baseline characteristics}

The final number of patients after exclusions was 68 in the periprosthetic group and 57 in the non-periprosthetic group. All patients were followed up for a minimum of 3 months (range 3-89 months, 22 months mean follow up), including patients who died within 3 months of their operation. Nine patients in the periprosthetic group and six patients in the non-periprosthetic group were considered as lost to follow up for the purpose of recording fracture union as these patients attended follow up in a different location and $\mathrm{x}$-rays were not accessible. These patients were included in the overall analysis as details regarding other outcomes such as postoperative mobility and mortality were accessible via an electronic record system for later unrelated attendances at the study hospital location.

A summary of patient baseline characteristics can be found in Table 1. In the periprosthetic group, mean age was 80.1 years (standard deviation (SD) 9.53; 95\% confidence interval (CI) 77.9-82.2) with 57 females and 11 males. In the non-periprosthetic group, mean age was 70.9 years (SD 18.6; 95\% CI 66.4-75.3) with 44 females and 13 males. $T$ tests for continuous variables and Fisher's exact test for categorical variables were applied to detect significant differences in baseline characteristics between groups, finding a significant difference in age $(p<0.001)$ between groups and a significantly greater number of patients with alcohol dependency in the non-periprosthetic group $(p=0.008)$.

Fracture comminution was present in 36/68 (53.0\%) periprosthetic fractures and 24/57 (42.1\%) non-periprosthetic fractures. Further, 32/68 (47.0\%) patients in the periprosthetic group and 29/57 (51.0\%) patients in the nonperiprosthetic group were treated using a submuscular or MIPO technique. Average plate and working length in the periprosthetic group was 12.6 and 4.6 holes respectively and 11.7 and 4.2 holes in the non-periprosthetic group.

\section{Comparison of outcomes of locked plating of periprosthetic and non-periprosthetic fractures}

A summary of main outcomes recorded for both groups can be found in Table 2. Mean time to union in the periprosthetic group was 4.2 months (SD 1.2 months) and 
Table 1 Patient baseline characteristics

\begin{tabular}{llll}
\hline Baseline characteristic & Periprosthetic $N=68$ & Non-periprosthetic $N=57$ & $p$ value \\
\hline Average age (years) & 80.1 & 70.9 & $<0.001$ \\
Gender & 57 Female (83.8\%) & 44 Female (77.2\%) & 0.530 \\
$\begin{array}{l}\text { Pre-operative walking aid } \\
\text { requirement/dependant }\end{array}$ & $36(53.0 \%)$ & $28(49.1 \%)$ & \\
living arrangement & & & 0.407 \\
Average BMl & 27.8 & 25.8 & $15(26.3 \%)$ \\
Smoking & $16(23.5 \%)$ & $15(26.3 \%)$ & 0.165 \\
Alcohol dependence & $6(8.8 \%)$ & $9(15.8 \%)$ & 0.610 \\
Diabetes mellitus & $17(25.0 \%)$ & $4(7.0 \%)$ & 0.008 \\
Steroids & $9(13.2 \%)$ & & 0.146 \\
\hline
\end{tabular}

$p$ values calculated using $T$ test and Fisher's exact test

4.7 months (SD 1.5 months) in the non-periprosthetic group. A survival analysis using competing risk modeling showed no significant difference in time to union $(p=0.827 ; 95 \%$ confidence interval: $0.70-1.55)$. Fiftyseven patients $(57 / 68,83.8 \%)$ in the periprosthetic group and 46 patients $(46 / 57,80.7 \%)$ in the non-periprosthetic group achieved union, with 11 and 12 patients respectively in each group going on to non-union. Conversely, the non-union rate was $16.2 \%$ in the periprosthetic group and $19.3 \%$ in the non-periprosthetic group. A Pearson chi-square test found no significant difference $(p=0.648)$ between groups with respect to non-union.

A high proportion of patients (periprosthetic 30/68, 44.1\%; non-periprosthetic 23/57, 40.4\%) had decreased function at long-term follow up. Fifteen patients in each group (periprosthetic 15/68, 22.1\%; non-periprosthetic 15/ $57,26.3 \%$ ) had died by the time the study was conducted. Chi-squared tests between both groups with respect to the incidence of decreased functionality $(p=0.800)$ and mortality $(p=0.566)$ showed no significant differences.

Ten patients $(10 / 68,14.7 \%)$ in the periprosthetic group and nine patients $(9 / 57,15.8 \%)$ in the non-periprosthetic group had recorded complications. A summary of recorded complications can be found in Table 3. The most common complication was plate failure and this was associated with non-union in 4/5 patients in the periprosthetic group and $2 / 4$ patients in the non-periprosthetic group. Fisher's exact test $(p=0.944)$ showed no significant differences between groups with regards to incidence of complication.

A similar number of patients in both groups (periprosthetic 9/68, 13.2\%; non-periprosthetic 8/57, 14.0\%) required revision surgery. A summary of revisions can be found in Tables 4 and 5. The commonest indication for revision was non-union. Fisher's exact test $(p=0.948)$ showed no significant differences between groups with regards to progression to revision surgery.

\section{Analysis of risk factors for non-union/positive association with union}

A summary of information regarding baseline characteristics, fracture types, and operative details for patients who went on to non-union can be found in Tables 6 and 7 . Risk factors for non-union assessed included age, gender, body mass index (BMI), smoking, diabetes mellitus, steroid medication use, alcohol dependence, fracture comminution, short plate, and working length (set at ten and four holes respectively) and use of an open technique.

A summary of the statistical analysis of risk factors for non-union and positive associations with union can be found in Tables 8 and 9. A Firth multivariable logistic model identified only comminution as a significant risk factor for non-union $(p=0.005)$. Other risk factors were found to be non-significant. Patients with comminuted fractures had a more than four times greater risk of non-union

Table 2 Outcomes

\begin{tabular}{llll}
\hline Outcome & Periprosthetic $N=68$ & Non-periprosthetic $N=57$ & $p$ value \\
\hline Mean time to union (months) & $4.2($ SD 1.2) & $4.7($ SD 1.5) & 0.827 \\
Non-union & $11(16.2 \%)$ & $12(21 \%)$ & 0.648 \\
Complication & $10(14.7 \%)$ & $9(15.8 \%)$ & 0.944 \\
Revision & $9(13.2 \%)$ & $8(14.0 \%)$ & 0.948 \\
Post-operative worse mobility/dependant & $30(44.1 \%)$ & $23(40.4 \%)$ & 0.800 \\
living arrangement & $15(22.1 \%)$ & $15(26.3 \%)$ & 0.566 \\
Mortality & & & \\
\hline
\end{tabular}

$p$ values calculated using survival analysis for mean time to union and Chi-squared test for remaining outcomes 
Table 3 Complications

\begin{tabular}{lll}
\hline Complication & $\begin{array}{l}\text { Periprosthetic } \\
N=10\end{array}$ & $\begin{array}{l}\text { Non-periprosthetic } \\
N=9\end{array}$ \\
\hline Plate failure & 5 & 4 \\
Infection & 1 & 2 \\
Deep vein thrombosis & 2 & 0 \\
$\begin{array}{l}\text { Symptomatic hardware } \\
\text { prominence requiring }\end{array}$ & 0 & 2 \\
removal & & \\
Peri-implant fracture & 0 & 1 \\
Pseudoaneurysm formation & 2 & 0 \\
\hline
\end{tabular}

compared to patients with non-comminuted fractures (odds ratio 4.60; 95\% confidence interval 1.60-13.17). The same multivariable model was applied to the above factors looking for positive association with union. Use of a submuscular technique $(p=0.006)$ and non-comminuted fracture patterns $(p=0.014)$ were significantly associated with achievement of union. A positive association with union was observed with use of a plate equal to or longer than ten holes in length $(p=0.065)$; however, this result was not statistically significant. Younger age, BMI (equal to or less than 25), gender, absence of smoking/diabetes/steroid use/alcohol dependence, and longer plate working length (equal to four holes or greater) were not found to have a significant positive association with union.

\section{Discussion}

To date, this study is the largest direct comparison of the outcomes of surgical treatment of distal femoral periprosthetic and non-periprosthetic fractures. No significant differences were found in outcomes between groups. Only one other paper was found directly comparing the outcomes of locked plating in these two groups (Song 2013 [14]). Despite reporting overall better union rates, outcomes between groups were also similar.

Distal femoral fractures are a challenging group of injuries for the orthopedic surgeon to treat [19]. This study has reflected what is already known in the literature regarding high rates of non-union, decreased post-operative functioning, and increased mortality. In particular, an overall non-union rate in both groups of $17.8 \%$ was comparable to reported rates in previous studies.

Table 4 Periprosthetic revisions

\begin{tabular}{lll}
\hline Revision & Indication & Periprosthetic $N=9$ \\
\hline $\begin{array}{l}\text { Revision fixation } \\
\text { with bone graft }\end{array}$ & Non-union & 4 \\
$\begin{array}{l}\text { Distal femoral } \\
\text { replacement }\end{array}$ & Non-union & 4 \\
$\begin{array}{l}\text { Revision total knee } \\
\text { replacement }\end{array}$ & $\begin{array}{l}\text { Tibial component } \\
\text { loosening }\end{array}$ & 1 \\
\hline
\end{tabular}

It could not be shown that the outcomes in the periprosthetic group would be worse than the non-periprosthetic group. Despite a 10-year age difference between groups, an almost equal number of patients in each group (accounting for $51.1 \%$ of patients in total) were considered frail through a surrogate measure of pre-morbid dependence on walking aids or living in an aged care facility. This reflects the incidence of distal femoral fractures as part of a spectrum of fragility fractures. As part of this spectrum, many similarities can be drawn between distal femoral and proximal femoral or hip fractures. Unlike hip fractures however, there is no widely accepted treatment algorithm or standard of care [20]. With increasing rates of arthroplasty especially in younger patients, periprosthetic fractures can be expected to rise in incidence [21]. Based on equal outcomes reported between groups in this study, a common approach to both periprosthetic and non-periprosthetic fractures should be utilized in future treatment algorithms. A notable exception to this is in the choice of fixation with a retrograde intramedullary nail, where a closed box design in prosthetic knees may preclude use of such a device [22].

In the secondary analysis of risk factors for non-union, comminution was identified as a strong predictor of nonunion. A systematic review of distal femoral non-unions showed metaphyseal comminution to be the most commonly associated fracture pattern [23]. The corollary to this observation-that simple fracture patterns are significantly more likely to progress to union, was also observed in the study. A positive association with union from use of a MIPO technique was demonstrated. This supports the theoretical benefit of submuscular plate insertion in preserving fracture site biology and therefore promoting better bone healing [24]. This relationship has been observed in a number of studies [25-27].

A positive trend toward union was observed in association with use of longer plates. This trend was not observed in conjunction with longer plate working lengths, where union rates are predicted to be improved as a result of reduced fixation rigidity, allowing for fracture site micromotion [28]. It is generally recommended that three to four holes should be left empty at the site of the fracture [29]. Although the average plate working length in both groups in this study was 4.4 holes, a positive relationship with union from this was not found. This is in keeping with a number of studies showing no or minimal correlation between longer working length and union $[25,30,31]$. Some studies have shown better healing with titanium versus stainless plates, proposed to be associated with reduced material stiffness [32, 33]. This relationship was not examined in this study as stainless steel plates were exclusively used.

Locked plating as applied to distal femoral fractures is still an evolving technique [34]. The benefit of locking plate technology in creating a fixed angle construct is 
Table 5 Non-periprosthetic revisions

\begin{tabular}{lll}
\hline Revision & Indication & Non-periprosthetic $N=8$ \\
\hline Revision fixation with bone graft & Non-union & 2 \\
Revision fixation with bone graft & Peri-implant fracture & 1 \\
Arthrodesis nail & Infected non-union & 1 \\
Distal femoral replacement & Non-union & 1 \\
Total knee replacement & Progression of osteoarthritis & 3 \\
\hline
\end{tabular}

attractive, especially as applied to elderly osteoporotic fracture patterns. In practice, plates are often applied without direct bony contact, in principle an 'internal' external fixator' [35]. This is often a necessity in periprosthetic fractures where the position of the femoral component may preclude optimal plate positioning. Although a number of studies have shown difficulties in achieving optimal plate fit in locking plate designs, there is as yet no clinical evidence to show any downside to this [7, 36]. As demonstrated in this study however, without bony union, locking plates still have a tendency to fail. There appears to be a beneficial effect on union from use of a submuscular technique, and use of this technique should be encouraged whenever possible, especially in simple fracture patterns. Achieving anatomical reduction in highly comminuted fractures may not always be achievable with lateral locking plates applied with a strictly MIPO technique. In particular, there exists concern for fixation failure and varus collapse in patients with medial comminution [37]. A case example in Fig. 2 is illustrative. In this setting, there may be a role for intramedullary fibular strut allograft use and or addition of a medial plate [38, 39]. Various aids to reduction in using MIPO technique, such as joystick pins, percutaneous clamps, and maximizing use of the plate as a reduction tool, have been described [19]. Further work is needed to determine an acceptable degree of reduction in application of MIPO technique, and whether the benefits of achieving anatomical reduction outweigh the invasiveness of the approach.

An alternative to fixation is arthroplasty. The results in this study lend support to the rationale to perform distal femoral replacement for elderly patients with highly comminuted distal femoral fractures. The greatest benefit here is the ability to allow the patient to commence full weightbearing postoperatively. Furthermore, by virtue of the treatment, the problem of non-union is eliminated. Significant concerns for regular adoption of

Table 6 Periprosthetic non-unions

\begin{tabular}{|c|c|c|c|c|c|c|c|c|c|c|c|c|}
\hline Patient & Age & Gender & $\begin{array}{l}\text { Fracture } \\
\text { classification }\end{array}$ & BMI & Smoking & $\begin{array}{l}\text { Diabetes } \\
\text { mellitus }\end{array}$ & $\begin{array}{l}\text { Steroid } \\
\text { medication }\end{array}$ & $\begin{array}{l}\text { Alcohol } \\
\text { dependence }\end{array}$ & $\begin{array}{l}\text { Plate } \\
\text { length } \\
\text { (holes) }\end{array}$ & $\begin{array}{l}\text { Working } \\
\text { length } \\
\text { (holes) }\end{array}$ & $\begin{array}{l}\text { Open (i.e., ORIF)/ } \\
\text { submuscular plate } \\
\text { insertion (i.e., MIPO) }\end{array}$ & Revision \\
\hline 1 & 81 & $F$ & $33 \mathrm{A3}$ & 29.8 & Y & N & Y & Y & 6 & 1 & ORIF & $\begin{array}{l}\text { Retrograde } \\
\text { nail + graft }\end{array}$ \\
\hline 2 & 73 & $\mathrm{~F}$ & $33 A 2$ & 24 & $\mathrm{~N}$ & N & N & Y & 16 & 2 & ORIF & $\begin{array}{l}\text { Distal femoral } \\
\text { replacement }\end{array}$ \\
\hline 3 & 89 & $\mathrm{~F}$ & $33 \mathrm{~A} 1$ & N/A & $\mathrm{N}$ & Y & $\mathrm{N}$ & $\mathrm{N}$ & 10 & 4 & ORIF & No \\
\hline 4 & 92 & $\mathrm{~F}$ & $33 \mathrm{~A} 1$ & 32 & $\mathrm{~N}$ & N & Y & $\mathrm{N}$ & 16 & 6 & MIPO & No \\
\hline 5 & 92 & $\mathrm{~F}$ & $33 A 2$ & 33.2 & $\mathrm{~N}$ & Y & N & $\mathrm{N}$ & 16 & 4 & MIPO & $\begin{array}{l}\text { Retrograde } \\
\text { nail + graft }\end{array}$ \\
\hline 6 & 90 & $\mathrm{~F}$ & $33 \mathrm{AB}$ & 24.2 & Y & N & N & $\mathrm{N}$ & 14 & 8 & MIPO & No \\
\hline 7 & 85 & M & $33 \mathrm{AB}$ & 20 & $\mathrm{~N}$ & N & N & $\mathrm{N}$ & 12 & 4 & ORIF & $\begin{array}{l}\text { Distal femoral } \\
\text { replacement }\end{array}$ \\
\hline 8 & 61 & M & $33 \mathrm{AB}$ & 48 & $\mathrm{~N}$ & Y & N & $\mathrm{N}$ & 12 & 6 & ORIF & $\begin{array}{l}\text { Revision } \\
\text { plate + graft }\end{array}$ \\
\hline 9 & 81 & $\mathrm{~F}$ & $33 \mathrm{~A} 3$ & 30 & $N$ & Y & N & $N$ & 14 & 2 & ORIF & No \\
\hline 10 & 79 & $\mathrm{~F}$ & $33 \mathrm{A3}$ & 22.1 & Y & N & Y & $\mathrm{N}$ & 12 & 5 & ORIF & $\begin{array}{l}\text { Distal femoral } \\
\text { replacement }\end{array}$ \\
\hline 11 & 75 & $\mathrm{~F}$ & $33 \mathrm{AB}$ & N/A & $\mathrm{N}$ & Y & Y & $\mathrm{N}$ & 14 & 4 & ORIF & No \\
\hline Average & 81.6 & $\begin{array}{l}81.8 \% \\
\text { female }\end{array}$ & $\begin{array}{l}81.8 \% \\
\text { comminution }\end{array}$ & 29.3 & $\begin{array}{l}27.3 \% \\
\text { smoking }\end{array}$ & $\begin{array}{l}45.5 \% \\
\text { diabetic }\end{array}$ & $\begin{array}{l}36.4 \% \\
\text { steroid } \\
\text { medication } \\
\text { use }\end{array}$ & $\begin{array}{l}18.2 \% \text { alcohol } \\
\text { dependence }\end{array}$ & 12.9 & 4.2 & $72.7 \%$ ORIF & \\
\hline
\end{tabular}


Table 7 Non-periprosthetic non-unions

\begin{tabular}{|c|c|c|c|c|c|c|c|c|c|c|c|c|}
\hline Patient & Age & Gender & $\begin{array}{l}\text { Fracture } \\
\text { classification }\end{array}$ & BMl & Smoking & $\begin{array}{l}\text { Diabetes } \\
\text { mellitus }\end{array}$ & $\begin{array}{l}\text { Steroid } \\
\text { medication }\end{array}$ & $\begin{array}{l}\text { Alcohol } \\
\text { dependence }\end{array}$ & $\begin{array}{l}\text { Plate } \\
\text { length } \\
\text { (holes) }\end{array}$ & $\begin{array}{l}\text { Working } \\
\text { length } \\
\text { (holes) }\end{array}$ & $\begin{array}{l}\text { Open (i.e., ORIF)/ } \\
\text { submuscular plate } \\
\text { insertion (i.e., MIPO) }\end{array}$ & Revision \\
\hline 1 & 51 & $\mathrm{~F}$ & $33 \mathrm{~A} 2$ & N/A & $N$ & N & N & $N$ & 10 & 5 & ORIF & No \\
\hline 2 & 95 & $F$ & $33 \mathrm{~A} 1$ & 22 & $\mathrm{~N}$ & $N$ & $N$ & $N$ & 12 & 6 & MIPO & No \\
\hline 3 & 93 & $\mathrm{~F}$ & $33 C 2$ & $\mathrm{~N} / \mathrm{A}$ & $N$ & $\mathrm{~N}$ & $\mathrm{~N}$ & $\mathrm{~N}$ & 10 & 4 & ORIF & No \\
\hline 4 & 56 & $\mathrm{~F}$ & $33 \mathrm{C} 1$ & N/A & $Y$ & N & N & Y & 8 & 3 & ORIF & No \\
\hline 5 & 48 & M & $33 \mathrm{~A} 1$ & N/A & Y & N & N & Y & 6 & 2 & ORIF & Arthrodesis \\
\hline 6 & 91 & F & $33 C 2$ & 16 & Y & N & N & $N$ & 6 & 2 & ORIF & No \\
\hline 7 & 47 & $\mathrm{~F}$ & $33 \mathrm{~A} 3$ & 40 & Y & Y & N & $\mathrm{N}$ & 12 & 3 & ORIF & $\begin{array}{l}\text { Revision } \\
\text { plate + graft }\end{array}$ \\
\hline 8 & 87 & $\mathrm{~F}$ & $33 \mathrm{~A} 3$ & 22.5 & $\mathrm{~N}$ & N & N & $\mathrm{N}$ & 12 & 4 & MIPO & No \\
\hline 9 & 78 & F & $33 \mathrm{AB}$ & 35 & $N$ & N & N & $N$ & 12 & 5 & MIPO & No \\
\hline 10 & 60 & $\mathrm{~F}$ & $33 \mathrm{AB}$ & 24.5 & $N$ & N & N & $N$ & 14 & 7 & ORIF & $\begin{array}{l}\text { Distal femoral } \\
\text { replacement }\end{array}$ \\
\hline 11 & 43 & M & $33 \mathrm{~A} 3$ & 23 & Y & N & N & Y & 14 & 3 & ORIF & $\begin{array}{l}\text { Retrograde } \\
\text { nail + graft }\end{array}$ \\
\hline 12 & 86 & F & $33 C 2$ & 21.9 & $N$ & N & N & $N$ & 14 & 3 & ORIF & No \\
\hline Average & 69.6 & $\begin{array}{l}83.3 \% \\
\text { female }\end{array}$ & $\begin{array}{l}75.0 \% \\
\text { comminution }\end{array}$ & 25.6 & $\begin{array}{l}41.7 \% \\
\text { smoking }\end{array}$ & $\begin{array}{l}8.3 \% \\
\text { diabetic }\end{array}$ & $\begin{array}{l}0.0 \% \\
\text { steroid } \\
\text { medication }\end{array}$ & $\begin{array}{l}25.0 \% \text { alcohol } \\
\text { dependence }\end{array}$ & 10.8 & 3.9 & 75.0\% ORIF & \\
\hline
\end{tabular}

this practice include the safety of performing complex surgery on frail patients, an increased risk of associated complications most especially infection and costs involved [40-42]. Recent studies reporting on the viability of distal femoral replacement as an option are promising [43-45], and future research efforts are required to better prove the safety and efficacy of this practice.

The influence of post-operative weightbearing instructions on patient outcomes and union rates merits consideration. As the practice of the study location was to make all patients non-weightbearing for a minimum of 6 weeks, analysis was not possible in this regard.

Table 8 Statistical analysis of risk factors for non-union

\begin{tabular}{ll}
\hline Risk factors for non-union & $p$ value \\
\hline Male sex & 0.424 \\
Age $\geq 75$ & 0.421 \\
BMI $>25$ & 0.235 \\
Smoking & 0.237 \\
Diabetes mellitus & 0.494 \\
Steroid medication & 0.138 \\
Alcohol dependence & 0.829 \\
Fracture comminution & 0.005 \\
Open procedure & 0.150 \\
Plate length < 10 & 0.529 \\
Working length $>4$ & 0.227 \\
\hline
\end{tabular}

$p$ values calculated using backwards stepwise logistic regression multivariable analysis
Although non-weightbearing is commonly the practice followed in many centres, recent studies $[7,46]$ have shown successful outcomes including high union rates in patients allowed full weightbearing after locked plating of distal femoral fractures. Although no biomechanical proof currently exists, there may be a beneficial effect on fracture site biology from weightbearing. There may be reluctance from surgeons to follow this practice, especially as locking plates are by definition load-bearing and not load-sharing devices and thus there may be concerns for early plate failure. However, there is much to

Table 9 Statistical analysis of positive associations with union

\begin{tabular}{lc}
\hline Positive association with union & $p$ value \\
\hline Male sex & 0.343 \\
Age $<75$ & 0.743 \\
BMI $\leq 25$ & $-^{\mathrm{a}}$ \\
Non-smoker & - \\
Nil diabetes mellitus & - \\
Nil steroid medication & - \\
Nil alcohol dependence & - \\
Simple fracture pattern & 0.019 \\
MIPO procedure & 0.008 \\
Plate length $\geq 10$ & 0.065 \\
Working length $\geq 4$ & - \\
\hline
\end{tabular}

${ }^{a}$ Variables without listed $p$ values were not found to be significant in the model building process and thus were not included in the final multivariable analysis 


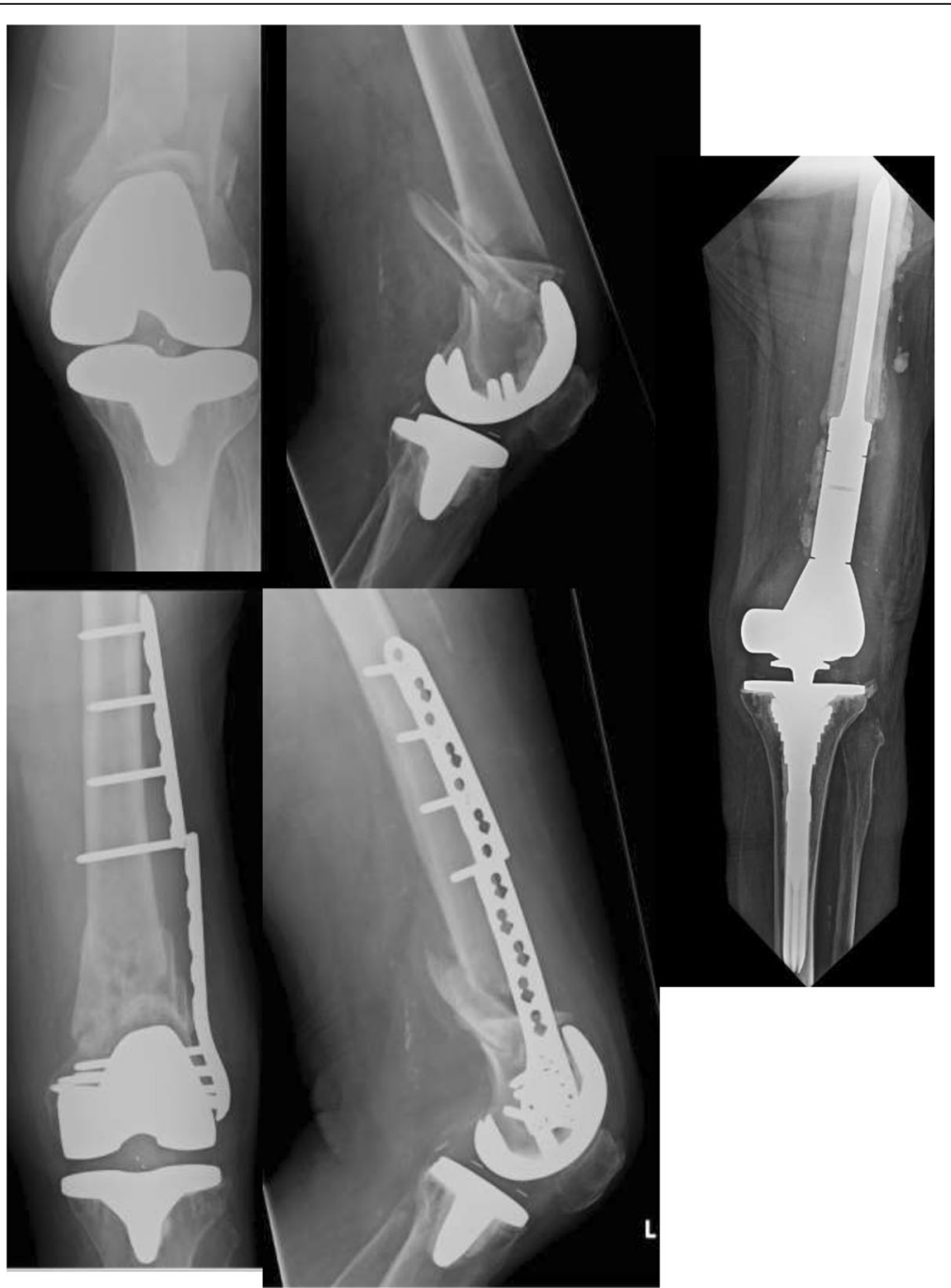

Fig. 2 Case example. It this case, the patient received a locking plate via an open technique with indirect reduction. The patient proceeded to non-union at 6-month follow up with consequent plate failure and was revised to distal femoral replacement

commend the practice of allowing full weight-bearing after treatment of distal femoral fractures, especially in elderly patients where avoidance of prolonged bed rest and its associated complications is desirable. This should be a standard of care in management of the elderly and future research efforts are needed to increase the clinical weight of evidence for this practice.

This study was limited by its retrospective design. Although locked plating was the predominant mode of fixation in the cohort of identified patients, exclusion of patients who were treated with different modalities may have created a selection bias. This study excluded patients with higher energy or open injuries representing the mostly younger end of the bimodal age distribution of distal femoral fractures. It was the intention of the study to focus on an elderly cohort with low energy closed injuries, and the results of this study should be applied specifically to this cohort. Despite overall consistency in locked plating operative technique at the study location, variations in technique between surgeons introduced heterogeneity to the reported results. Patient-reported outcomes were not performed, and ideally these should have been performed to determine the clinical significance of the results.

\section{Conclusions}

In conclusion, no differences were found in outcomes of locked plating of periprosthetic and non-periprosthetic distal femoral fractures. Therefore, a common approach to both fractures is advocated. This will aid future research efforts in determining an acceptable algorithm for treatment of this fracture. Non-union remains the greatest challenge facing surgeons in management of distal 
femoral fractures. A significantly increased risk of nonunion exists in patients with comminuted fractures. Surgeons should be aware of the potential for non-union in managing such patients. Future studies are needed to investigate efforts to improve union rates in locking plate fixation of highly comminuted fractures.

\section{Abbreviations}

AO: Arbeitsgemeinschaft für Osteosynthesefragen; AP: Anteroposterior; ASA: American Society of Anesthesiologists; BMI: Body mass index; Cl: Confidence interval; DRG: Diagnosis-related group; LCP: Locking compression plate; MIPO: Minimally invasive plate osteosynthesis; SD: Standard deviation

\section{Acknowledgments}

Not applicable.

\section{Funding}

The authors declare that no funding was received for this study.

\section{Availability of data and materials}

The datasets used and analyzed during the current study are available from the corresponding author on reasonable request

\section{Authors' contributions}

JK designed the study, collected data, and wrote the manuscript. PC assisted with data collection. MD provided statistical analysis and editing of the manuscript. MH provided senior supervision. All authors read and approved the final manuscript

\section{Ethics approval and consent to participate}

This study was given ethics approval by the Central Coast Local Health District Research Board. Informed consent was not required for this study.

\section{Consent for publication}

Not applicable.

\section{Competing interests}

The authors declare that they have no competing interests.

\section{Publisher's Note}

Springer Nature remains neutral with regard to jurisdictional claims in published maps and institutional affiliations.

\section{Author details}

${ }^{1}$ Gosford District Hospital, Central Coast Local Health District, Gosford, NSW 2250, Australia. ${ }^{2}$ School of Medicine and Public Health, University of Newcastle, Callaghan, NSW 2308, Australia.

Received: 13 February 2019 Accepted: 17 May 2019

Published online: 24 May 2019

\section{References}

1. Moloney GB, Pan T, Van Eck CF, Patel D, Tarkin I. Geriatric distal femur fracture: are we underestimating the rate of local and systemic complications? Injury. 2016;47:1732-6.

2. Chen F, Mont MA, Bachner RS. Management of ipsilateral supracondylar femur fractures following total knee arthroplasty. J Arthroplast. 1994;9:521-6.

3. Australian Orthopaedic Association National Joint Replacement Registry (AOANJRR). Hip, knee \& shoulder arthroplasty: 2018 annual report. Adelaide: AOA; 2018.

4. Matlovich NF, Lanting BA, Vasarhelyi EM, Naudie DD, McCalden RW, Howard $J$. Outcomes of surgical management of supracondylar periprosthetic femur fractures. J Arthroplast. 2017:32:189-92.

5. Griffin XL, Parsons N, Zbaeda MM, McArthur J. Interventions for treating fractures of the distal femur in adults. Cochrane Database Syst Rev. 2015;8: CD010606.
6. Konan S, Sandiford N, Unno F, Masri BS, Garbuz DS, Duncan CP. Periprosthetic fractures associated with total knee arthroplasty: an update. Bone Joint J. 2016;98-B:1489-96.

7. Poole WEC, Wilson DGG, Guthrie HC, Bellringer SF, Freeman R, Guryel E, et al. 'Modern' distal femoral locking plates allow safe, early weight-bearing with a high rate of union and low rate of failure. Bone Joint J. 2017;99-B: 951-7.

8. Ebraheim NA, Kelley LH, Liu X, Thomas IS, Steiner RB, Liu J. Periprosthetic distal femoral fracture after total knee arthroplasty: a systematic review. Orthop Surg. 2015;7:297-305

9. Rodriguez EK, Boulton C, Weaver MJ, Herder LM, Morgan JH, Chacko AT, et al. Predictive factors of distal femoral fracture non-union after lateral locked plating: a retrospective multicentre case-control study of 283 fractures. Injury. 2014;45:554-9.

10. Christ AB, Chawla H, Gausden EB, Villa JC, Wellman DS, Lorich DG, et al. Radiographic and clinical outcomes of periprosthetic distal femur fractures treated with open reduction and internal fixation. J Orthop Trauma. 2018; 32(10):515-20.

11. Streubel PN, Ricci WM, Wong A, Gardner MJ. Mortality after distal femur fractures in elderly patients. Clin Orthop Rel Res. 2011;469:118-96.

12. Ebraheim NA, Liu J, Hashmi S, Sochacki KR, Moral MZ, Hirschfeld AG. High complication rate in locking plate fixation of lower periprosthetic distal femur fractures in patients with total knee arthroplasties. J Arthroplast. 2012; 27(5):809-13.

13. Kammerlander C, Riedmuller P, Gosch M, Zegg M, Kammerlander-Knauer U, Schmid $\mathrm{R}$, et al. Functional outcome and mortality in geriatric distal femur fractures. Injury. 2012;43:1096-101.

14. Song SJ, Kim Kl, Song WJ, Kim DK, Bae DK. Treatment of distal femur fractures with locking plates: comparison of periprosthetic fractures above total knee arthroplasty and non-periprosthetic fractures. Acta Orthop Bel. 2014;80:380.

15. Australian Consortium for Classification Development. AR-DRG - version 9.0 Final Report 2016

16. AO/OTA. Fracture and dislocation compendium-2018. J Orthop Trauma. 2018;32(1):40-3.

17. Buckley RE, Moran CG, Apivatthakakul TAO. Principles of fracture management. 3rd ed. Stuttgart: Thieme; 2018.

18. Corrales LA, Morshed S, Bhandari M, Miclau T, Henant H. Variability in the assessment of fracture healing in orthopaedic trauma studies. J Bone Joint Surg. 2008;90:1862-8.

19. Pietu G, Ehlinger M. Minimally invasive internal fixation of distal femur fractures. Orthop Traumatol Surg Res. 2017;103:S161-9.

20. Smith JR, Halliday R, Aquilina AL, Morrison RJ, Yip GC, McArthur J, et al. Distal femoral fractures: the need to review the standard of care. Injury. 2015;46(6):1084-8

21. Ristevski B, Nauth A, Williams DS, Hall J, Whelan DB, Bhandari M, et al. Systematic review of the treatment of periprosthetic distal femur fractures. $J$ Orthop Trauma. 2014;28(5):307-12.

22. Thompson SM, Lindisfarne EAO, Bradley N, Solan M. Periprosthetic supracondylar femoral fractures above a Total knee replacement: compatibility guide for fixation with a retrograde intramedullary nail. J Arthroplast. 2014:29:1639-41.

23. Ebraheim NA, Martin A, Sochacki KR, Liu J. Non union of distal femoral fractures: a systematic review. Orthop Surg. 2013:5:46-50.

24. Farouk O, Krettek C, Miclau T, Schandelmaier P, Guy P, Tscherne H. Minimally invasive plate osteosynthesis: does percutaneous plating disrupt femoral blood supply less than the traditional technique? J Orthop Trauma. 1999:13(6):401-6.

25. Hoffman MF, Jones CB, Sietsma DL, Tornetta P, Koenig SJ. Clinical outcomes of distal femoral fractures in a retrospective cohort. J Orthop Surg Res. 2013;8:43.

26. Hou Z, Bowen TR, Irgit K, Strohecker K, Matzko ME, Widmaier J, et al. Locked plating of Periprosthetic fractures above total knee Arthroplasty. J Orthop Trauma. 2012;26(7):427-32

27. Doshi HK, Wenzian P, Burgula MV, Murphy DP. Clinical outcomes of distal femoral fractures in the geriatric population using locked plates with a minimally invasive approach. Geriatr Orthop Surg Rehabil. 2013; 4(1):16-20.

28. Mardian S, Schaser K, Duda GN, Heyland M. Working length of locking plates determines interfragmentary movement in distal femur fractures under physiological loading. Clin Biomech. 2015;30:391-6.

29. Smith WR, Ziran BH, Anglen JO, Stahel PH. Locking plates: tips and tricks. J Bone Joint Surg. 2007;89-A(10):2298-307. 
30. Henderson CE, Lujan TJ, Kuhl LL, Bottlang M, Fitzpatrick DC, Marsh JL. Healing complications are common after locked plating for distal femur fractures. Clin Orthop Rel Res. 2011;469:1757-65.

31. Bottlang M, Doornink J, Lujan TJ, Fitzpatrick DC, Marsh JL, Augat P, et al. Effects of construct stiffness on healing of fractures stabilised with locking plates. J Bone Joint Surg. 2010;92:12-22.

32. Rodriguez EK, Zurakowski D, Herder L, Hall M, Walley KC, Weaver MJ, et al. Mechanical construct characteristics predisposing to non-union after locked plating of distal femur fractures. J Orthop Trauma. 2016;30(8):403-8.

33. Lujan TJ, Henderson CE, Madey SM, Fitzpatrick DC, Marsh JL, Bottlang M. Locked plating of distal femur fractures leads to inconsistent and asymmetric callus formation. J Orthop Trauma. 2010;24(3):156-62.

34. Ehlinger M, Dujardin F, Pidhorz L, Bonnevialle P, Pietu G, Vandenbussche E. Locked plating for internal fixation of the adult distal femur: influence of the type of construct and hardware on the clinical and radiological outcomes. Orthop Traumatol Surg Res. 2014;100:549-54.

35. Yarboro SR. Lateral distal femur plate for periprosthetic fracture. J Orthop Trauma. 2018;38(8-1):30-1.

36. Hwang JH, Oh JK, Oh CW, Yoon YC, Choie HW. Mismatch of anatomically pre-shaped locking plate on Asian femurs could lead to malalignment in the minimally invasive plating of distal femoral fractures: a cadaveric study. Arch Orthop Trauma Surg. 2012;132:51-6.

37. Peschiera V, Staletti L, Cavanna M, Saporito M, Berlusconi M. Predicting the failure in distal femur fractures. Injury. 2018;49(3):S2-7.

38. Kumar A, Chambers I, Maistrelli G, Wong P. Management of periprosthetic fracture above total knee arthroplasty using intramedullary fibular allograft and plate fixation. J Arthoplasty. 2008;23(4):554-8.

39. Chen SH, Tai CL, Yu TC, Wang CW, Lin CW, Chen CY, et al. Modified fixations for distal femur fractures following total knee arthroplasty: a biomechanical and clinical relevance study. Knee Surg Sports Traumatol Arthrosc. 2016; 24(10):3262-71.

40. Mortazavi J, Kurd MF, Bender B, Post Z, Parvizi J, Purtill JJ. Distal femoral arthroplasty for the treatment of periprosthetic fractures after total knee arthroplasty. J Arthroplast. 2010;25:775-80

41. Jassim SS, McNamara I, Hopgood P. Distal femoral replacement in periprosthetic fracture around total knee arthroplasty. Injury. 2014;45:550-3.

42. Hoellwarth JS, Fourman MS, Crossett L, Goodman M, Siska P, Moloney GB, et al. Equivalent mortality and complication rates following periprosthetic distal femur fractures managed with either lateral locked plating or a distal femoral replacement. Injury. 2018;49:392-7.

43. Rahman WA, Vial TA, Backstein DJ. Distal femoral arthroplasty for management of periprosthetic supracondylar fractures of the femur. J Arthroplast. 2016;31:676-9.

44. Hart GP, Kneisl JS, Springer BD, Patt JC, Karunakar MA. Open reduction vs. distal femoral replacement arthroplasty for comminuted distal femur fractures in the patients 70 years and older. J Arthroplast. 2017;32:202-6.

45. Atrey A, Hussain N, Gosling O, Giannoudis P, Shepherd A, Young S, et al. A 3 year minimum follow up of Endoprosthetic replacement for distal femoral fractures—an alternative treatment option. J Orthop. 2017;14:216-22.

46. Smith WR, Stoneback JW, Morgan SJ, Stahel PF. Is immediate weight bearing safe for periprosthetic distal femur fractures treated by locked plating? A feasibility study in 52 consecutive patients. Patient Safety Surg. 2016;10:2.

Ready to submit your research? Choose BMC and benefit from:

- fast, convenient online submission

- thorough peer review by experienced researchers in your field

- rapid publication on acceptance

- support for research data, including large and complex data types

- gold Open Access which fosters wider collaboration and increased citations

- maximum visibility for your research: over $100 \mathrm{M}$ website views per year

At BMC, research is always in progress.

Learn more biomedcentral.com/submissions 